\title{
Establishment of a Reformed Chinese-English Bilingual Teaching System of Pharmacology in Tianjin University of Science and Technology, China
}

\author{
Xue-Gang Luo*, Ai Mu, Wen-Wen Zhao, Xiao-Ying Chen, Jing-Jie Li, Chao-Hui Sun, Tong-Cun Zhang \\ Department of Pharmaceutical Engineering College of Biotechnology, Tianjin University of Science and Technology, Tianjin, China.
}

\begin{abstract}
With the rapid development of pharmaceutical industry and the requirement of economic globalization, the demand of international pharmaceutical professionals in China has been kept increasing. In this project, to set up a Chinese-English bilingual teaching system of pharmacology for undergraduate students majored in Pharmaceutical Engineering, a survey had been conducting to evaluate the general talents and attitudes of students and the need of the industry for 7 years in Tianjin University of Science and Technology, the teaching contents were then adjusted and optimized to highlight the application ability of professional English on the basis of the emphasis of pharmacology knowledge. Basing on these works, a novel Chinese-English bilingual textbook of pharmacology was published in 2013, and an open and multi-mode reformed Chinese-English bilingual education system was also established in the university. In our opinion, this novel textbook and the teaching system might throw light to the bilingual education of pharmacology in China.
\end{abstract}

Key words: Chinese-English bilingual education, Pharmacology, Pharmaceutical Engineering, Textbook reform, China.

\section{INTRODUCTION}

In 1998, Pharmaceutical Engineering, a novel major, was approved by the Ministry of Education of China. One year later, this major was established in 34 universities and 1165 under graduate students were enrolled. Considerably, the number of universities and enrolled students were rapidly increased to 199 and 12064 respectively after 10 years.

In the recent 30 years, the pharmaceutical industry in China has obtained rapid development. In nowadays, the number of China's drug manufacturing firms is more than 5,000. ${ }^{1}$ The pharmaceutical processing capacity has ranked first in the world, and the production of chemical raw materials and intermediates has ranked second worldwide. The production of chemical raw materials has been up to more than 1,300 varieties, and the total annual output has been more than 800,000 tons, of which nearly $50 \%$ was exported to abroad, accounting for $25 \%$ of the world trade. Although sales of pharmaceutical products in China market are still mainly depended on domestic demand, for example, the export delivery value of pharmaceutical products only accounted for $12.65 \%$ of all sales of pharmaceutical products in 2006, many analysts predict China will be the world's second largest drug-producing country after the United States by $2020 .^{2}$ In addition, China has joined the World Trade Organization (WTO) for over ten years, and this makes China's economy participate in economic globalization and international competition more deeply and fully. ${ }^{3}$ Taken together, these factors undoubtedly require internationalization of students majored in Pharmaceutical Engineering.
Submission Date :13/08/2014 Revision Date :03/09/2014 Accepted Date : :23/12/2014

DOI: $10.5530 /$ ijper.49.1.4

Correspondence Address Prof: Xue-Gang Luo, PhD,

Tianjin University of Science and Technology,

No.29, 13th Street,

Economic-Technological

Development Area,

Tianjin 300457, P.R. China.

Tel: 86-22-60601104,

Email: luoxuegang@ hotmail. com.

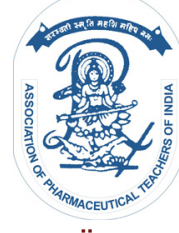

www.ijper.org 
Pharmacology is the discipline that builds the connection between medicine and pharmaceutics as well as the drugs development and clinical applications. To undergraduate students majored in Pharmaceutical Engineering, pharmacological knowledge is beneficial for their progress and job in the future. On the other hand, with the rapid evolvement of biomedicine, in order to enhance the international competition of Chinese pharmaceutical disciplines and industry, it is necessary to train the students with both pharmacological knowledge and the capacity of communicating by foreign language, especially English. In view of this, Tianjin University of Science and Technology has attached great importance to Chinese-English bilingual pharmacological teaching practice since the major of Pharmaceutical Engineering was set up. At the same time, we also took steps into exploring innovative means of Chinese-English bilingual education and accumulated a couple of valuable experience as well.

\section{MAJOR METHODS OF THE PROJECT}

The major of Pharmaceutical Engineering in Tianjin University of Science and Technology was established in 2000, and the Chinese-English bilingual teaching system of pharmacology has been kept exploring since 2006. Up to now, about 750 students had participated in the study of this bilingual class. In each year, a student survey was conducted to evaluate the general talents and attitudes of students, and the feedback advices were collected anonymously from all students. The contents and teaching style were then kept adjusting in the next year based on these recommendations. In addition, the status of Chinese-English bilingual education of pharmacology in Pharmaceutical Engineering major in the other university in China was also investigated during the past 7 years. Finally, On the basis of the accumulated experience and investigation, a novel Chinese-English bilingual textbook of pharmacology was written by 23 teachers who have been teaching the lesson of pharmacology in 20 different universities or academies in China, and the reformed Chinese-English bilingual education system was established.

\section{RESULTS AND DISCUSSION}

Altogether 748 students participated in the study of this Chinese-English bilingual class of pharmacology. Among the participants, $52.67 \%$ were female and $47.33 \%$ were male. Before our textbook, three different versions of pharmacology textbook have been used during this study.

The investigation on the current status of ChineseEnglish bilingual education of pharmacology in

\section{Pharmaceutical Engineering major in China}

There were merely 34 colleges and universities recruiting students on Pharmaceutical Engineering in 1999, including 13 medical colleges, 12 colleges of technology and science, and 9 comprehensive universities. However, up to now, more than 100 universities and colleges have setting up this subject and with a larger proportion of non-medical institutions. As an important specialized course in Pharmaceutical Engineering, pharmacology is set in all the universities and colleges. However, when we started our attempt of the Chinese-English bilingual education on pharmacology, we found that several issues were needed to be realized and solved urgently:

(1) Comparing with medical universities, non-medical universities have differences in personnel training and teacher resources in the medical and pharmaceutical area. As there has no sufficient basic medical curriculums and background knowledge to sustain the deeply pharmacological study of students, non-medical university could not directly copy the teaching approaches of medical institutions, or it would lead to the educational failure.

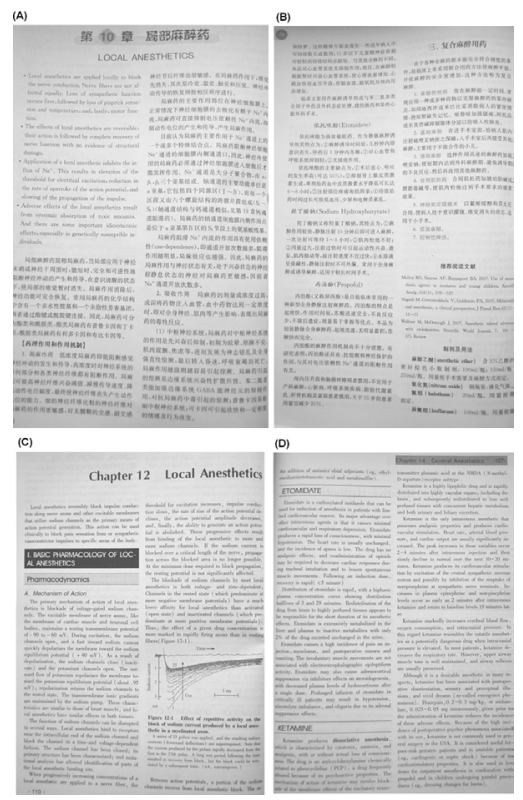

Figure 1: Typical pharmacological textbooks in China. (A)-(D) showed several typical Chinese-English bilingual pharmacological textbooks in China.

(2) At present, the Chinese-English bilingual pharmacological textbook which is suitable for undergraduate students is lacked in China. Most of current ChineseEnglish bilingual textbooks just only mark the name of classic drugs in English on the basis of Chinese version. Besides, some versions of Chinese-English bilingual textbooks are nearly full of English language, and 
ignore the general talent of Chinese undergraduates (Figure 1).

(3) Current versions of the pharmacological textbook are somewhat outdated. The terms and contents have not been updated in time. For example, they are merely focused to the chemical drugs, whereas the biological drugs which have been used widely in clinic are still thimbleful involved in the book.

(4) Currently, the teaching method of pharmacological education in China is still rested on the traditional indoctrination style, and is deficient in interaction between students and teachers and lack of practicing in science and industry. As a consequence, it would be difficult to help students obtain independent and innovative ideas.

\section{Optimization of the teaching contents}

In China, the Pharmacology course in the major of Pharmaceutical Engineering mostly takes only about 40 class hours. Therefore, in order to make students master essential pharmacological knowledge in the limited time, it's necessary to optimize the teaching content. Therefore, some efforts were performed in our project as follows:

On one hand, we analyzed and compared the current major version of pharmacology textbooks and the guidance of the Instructive Committee of Education of Pharmaceutical Engineering Major in China, and then determined the appropriate teaching contents which are suitable for Chinese undergraduate students majored in Pharmaceutical Engineering. Briefly, 1-3 typical drugs in each category were selected as representatives. Focused around these typical drugs, the basic theories and key terms were expatiated deeply, and the other drugs and contents were just condensed.

On the other hand, the teaching content of pharmacology textbook was updated to adapt the development of the pharmaceutical industry. For example, many biological drugs (such as interferon, interleukin and other cytokines, rituximab and other monoclonal antibody drugs, etc) have been widely used in clinic for many years, their pharmacological effects and adverse reactions are exact. However, the biological drugs have not been mentioned in most pharmacology textbooks. Therefore, a chapter focusing on this type of drugs was added in our class and textbook.

Finally, in order to obtain the desired effects in the limited time, the period distribution was set as showed in Table 1.

\section{Highlighting the applicability of professional English}

In essence, Chinese-English bilingual education is neither Chinese lingual education nor English lingual
Table 1: Period distribution of the Chinese-English bilingual teaching of pharmacology

\begin{tabular}{|l|c|}
\hline \multicolumn{1}{|c|}{ Chapter } & $\begin{array}{c}\text { Class } \\
\text { hour* }\end{array}$ \\
\hline Overview of Pharmacokinetics & 4 \\
\hline Overview of Pharmacodynamics & 4 \\
\hline $\begin{array}{l}\text { Overview of the Autonomic and Somatic Motor } \\
\text { Nervous Systems }\end{array}$ & 1 \\
\hline Cholinergic Receptor Agonists Agents & 1 \\
\hline Anticholinesterase Agents and Reactivators & 1 \\
\hline Cholinergic Receptor Antagonists Agents & 2 \\
\hline Adrenergic Agonists & 2 \\
\hline Adrenergic Receptor Antagoinists & 2 \\
\hline Hypnotics and Sedatives & 1 \\
\hline Treatment of Central Nervous System & 2 \\
\hline $\begin{array}{l}\text { Degenerative Disorders and Antipsychoses } \\
\text { Agents }\end{array}$ & 2 \\
\hline Opioid Analgesics & 2 \\
\hline $\begin{array}{l}\text { Analgesic-Antipyretic and Antiinflammatory } \\
\text { Agents }\end{array}$ & 2 \\
\hline Antiarrhythmic Drugs & 2 \\
\hline Drugs Used for Therapy of Hypertension & 2 \\
\hline Pharmacotherapy of Congestive Heart Failure & 2 \\
\hline $\begin{array}{l}\text { Drug for Therapy of Dyslipidemia and } \\
\text { Antiatherogenic }\end{array}$ & 2 \\
\hline Pharmacotherapy of Asthma & 2 \\
\hline Drugs Affecting Gastrointestinal Function & 2 \\
\hline Adrenocorticosteroids & 2 \\
\hline Hypoglycemic Agents & 2 \\
\hline Antimicrobial Agents & 2 \\
\hline Antineoplastic Agents & 2 \\
\hline Overview of Biological Drugs & 2 \\
\hline Total & 2 \\
\hline * One class hour is 45 min. & 2 \\
\hline
\end{tabular}

education. Its ultimate goal is to make students familiar with the English on the basis of a deep grasp of pharmacology knowledge. ${ }^{4}$ Therefore, in our opinion, in order to achieve a real Chinese-English bilingual education, it is necessary to carry out the following works:

(1) In China, the main content of the textbook should be written by Chinese. However, important terms or drugs, and all the figures, tables and notes should be given in English. What' more, the key knowledge points should be given at Chinese-English bilingual style.

(2) A list of important pharmacological words that involved in each chapter should be attached after the text. In addition, because of the characteristic that most pharmacological words are formed by etyma, these professional etyma should be collated and analyzed, and also attached in the related chapter to facilitating students' learning. 
(3) At the end of each chapter, some English quiz should be listed to make students think and review the emphasis. In addition, some classic English papers should also be recommended to students, and English seminar should be held regularly to improve the application ability of professional English.

\section{Writing and publishing a novel Chinese-English bilingual textbook of pharmacology}

On the basis of the accumulated experience and investigation in the past 7 years, a novel ChineseEnglish bilingual textbook of pharmacology was written by 23 scholars from 20 different institutions, and published by Huazhong University of Science and Technology Press (ISBN NO. 978-7-5609-90026) on Aug 2013. As shown in Figure 2, in this novel bilingual textbook, the contents had been optimized (for example, a chapter focusing on biotech drugs was added in the book), the key knowledge points were written at Chinese-English bilingual style, a list of important pharmacological words was given in each chapter, and the professional etymons were collated and analyzed. In the past year, this textbook has been used in several universities in China, including of Tianjin University of Science and Technology, Three Gorges University, Mianyang Normal University, etc.

\section{Founding an open and multi-mode teaching system}

In order to obtain the best teaching effects, an open and multi-mode teaching system was established. Briefly, multimedia and methods, including of blackboard writing, computers, pictures, videos, models, and so on, were used during the teaching. English seminar around classic English papers and the development of the pharmacology discipline and pharmaceutical industry were held regularly. Domestic and foreign pharmacology experts were invited to give classes or reports as mush as possible, and every students were requested to have extracurricular practice, such as participating in the conference whose topic is related to pharmacology, writing scientific articles, etc, at least once during the lesson. In addition, the assessment of students were more diversification, and the final score was include scores of test, presentation and any other practices associated with the Chinese-English bilingual course of pharmacology (Figure 3).

\section{CONCLUSION}

The Chinese-English bilingual education is a new teaching way, which can improve teaching level and accelerate the internationalization of higher education. Considering the needs of the international development of the
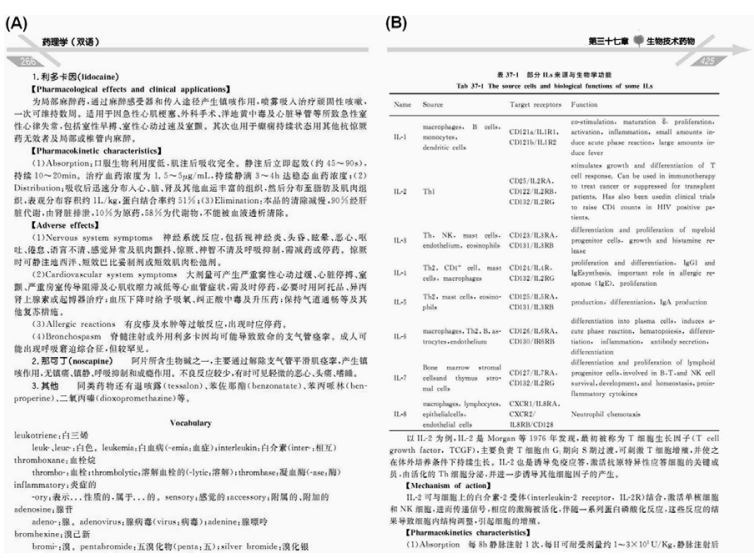

Figure 2: The Chinese-English bilingual pharmacological textbook published by the present project.

(A)-(B) showed typical pages in our textbook.

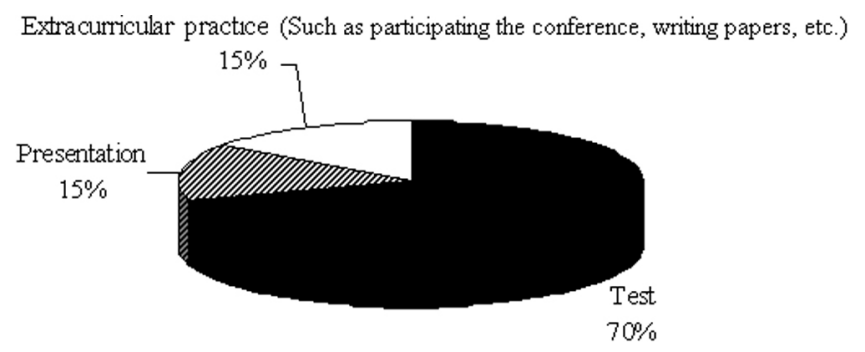

Figure 3: Assessment of students in the new Chinese-English bilingual education system of pharmacology. 
pharmaceutical industry in China, a reform program focusing on the Chinese-English bilingual education of pharmacology was performed in our university in the past 7 years, the teaching contents was optimized to fit the general talents of Chinese undergraduate students and the need of China's pharmaceutical industry, the applicability of professional English was highlighted on the basis of the emphasis of pharmacology knowledge, and an open and multi-mode teaching system was founded as well. In our opinion, the novel textbook published by us and the experience gained in this project would throw light to the Chinese-English bilingual education of pharmacology in universities in China.

\section{ACKNOWLEDGMENT}

This research was financially supported by the Foundation for Educational and Reaching Reform of the
Tianjin University of Science and Technology (NO. C12, NO. C13), and the project entitled "Practice and Demonstration of the Chinese-English bilingual education in the Engineering Associated Disciplines", which was supported by the Research Program of Teaching Quality and Reform for Undergraduate of the Ordinary College in Tianjin.

\section{REFERENCES}

1. Sun Q, Santoro MA, Meng Q, Liu C. Eggleston K. Pharmaceutical policy in China. Health. Aff (Millwood). 2008; 27(4): 1042-50.

2. Cyranoski D. Pharmaceutical futures: made in China? Nature 2008; 455(7217): 1168-70

3. Liang W. China: globalization and the emergence of a new status quo power? Asian Perspective 2007; 31(4): 125-49.

4. Xin Luo. Present Positions and Suggestions of Bilingual Education for High Education in China. Advances in Intelligent and Soft Computing 2012; 149: 473-7W. 